\title{
Short interfering RNA against STAT1 attenuates cisplatin-induced ototoxicity in the rat by suppressing inflammation
}

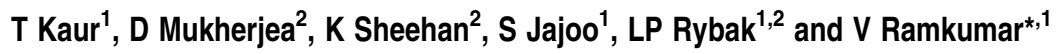

Cisplatin is widely used for treating various solid tumors. However, this drug produces dose-limiting ototoxicity and nephrotoxicity, which significantly reduce the quality of life of cancer patients. While nephrotoxicity could be alleviated by diuresis, there is currently no approved treatment for hearing loss. Previous studies show that the ROS and inflammation are major contributors to cisplatin-induced hearing loss. In this study, we show that ROS trigger the inflammatory process in the cochlea by activating signal transducer and activator of transcription-1 (STAT1). Activation of STAT1 activation was dependent on ROS generation through NOX3 NADPH oxidase, knockdown of which by siRNA reduced STAT1 activation. Moreover, STAT1 siRNA protected against activation of p53, reduced apoptosis, reduced damage to OHCs and preserved hearing in rats. STAT1 siRNA attenuated the increase in inflammatory mediators, such as TNF- $\alpha$, inhibition of which protected cells from cisplatinmediated apoptosis. Finally, we showed that trans-tympanic administration of etanercept, a TNF- $\alpha$ antagonist, protected against OHC damage and cisplatin-induced hearing loss. These studies suggest that controlling inflammation by inhibition of STAT1dependent pathways in the cochlea could serve as an effective approach to treat cisplatin ototoxicity and improve the overall quality of life for cancer patients.

Cell Death and Disease (2011) 2, e180; doi:10.1038/cddis.2011.63; published online 21 July 2011

Subject Category: Cancer

Ototoxicity and nephrotoxicity are common side effects of cisplatin in cancer chemotherapy. However, unlike nephrotoxicity, which could be alleviated by diuresis and antioxidants, ototoxicity is more difficult to treat, owing primarily to an incomplete understanding of the mechanism(s) involved in this process. The generation of reactive oxygen species (ROS) is considered critical for producing cisplatin ototoxicity. ${ }^{1}$ However, it is not entirely clear how ROS contribute to cisplatin ototoxicity.

ROS serve as a principal mediator of damage to outer hair cells (OHCs). ROS are produced primarily by the cochlearspecific NADPH oxidase isoform, nitro-L-arginine methyl ester (NOX3), ${ }^{2}$ which is activated and induced by cisplatin. Scavenging of ROS by antioxidants reduces the cisplatininduced expression of NOX3 ${ }^{3,4}$ ROS produced through NOX 3 induce the expression of a number of genes, including transient receptor vanilloid-1 (TRPV1) channels in the OHCs, activation of which promotes apoptosis. Knockdown of TRPV1 by round window application of short interfering RNA (siRNA) reduces cisplatin-induced hearing loss in rats, ${ }^{3}$ suggesting that this could be an effective otoprotective strategy.

The role of inflammation in the development of hearing loss was suggested from evidence that corticosteroid protected against sensorineural hearing loss. ${ }^{5}$ Later studies demonstrate that the cochlea can mount an inflammatory response as a result of immune challenges or toxic insults. Proinflammatory cytokines, such as interleukin-1 $\beta$ (IL-1 $\beta)$ and tumor necrosis factor- $\alpha$ (TNF- $\alpha$ ), increase inflammatory mediators in cultured spiral ligament (SL) fibrocytes. ${ }^{6}$ Induction of inflammation in the mouse cochlea was observed following antigen challenge to the inner ear. ${ }^{7}$ Recent studies have implicated inflammation in cisplatin-induced cell death. For example, cisplatin increased the expression of inflammatory cytokines in UB/UE1 utricular epithelial cells, and in the cristae ampullae and utricles isolated from mice. ${ }^{8}$ Cisplatin also mediates inflammation in the cochlea which was attenuated by flunarizine, an activator of NF-E2-related factor-2 (Nrf2)/heme oxygenase-1 (HO-1). ${ }^{9}$

\footnotetext{
${ }^{1}$ Department of Pharmacology, Southern Illinois University School of Medicine, Springfield, IL 62794-9629, USA and ${ }^{2}$ Department of Surgery, Southern Illinois University School of Medicine, Springfield, IL 62794-9629, USA

*Corresponding author: V Ramkumar, Department of Pharmacology, Southern Illinois University School of Medicine, PO Box 19629, Springfield, IL 62794-9629, USA. Tel: + 217545 2171; Fax: + 217545 0145; E-mail: vramkumar@ siumed.edu

Keywords: cisplatin; hearing loss; STAT1; cochlea; inflammation; apoptosis

Abbreviations: $A B R$, auditory brainstem response; AP-1, activator protein-1; COX-2, cyclooxygenase 2; $C D$, cluster of differentiation; dB, decibel; DAPI, 4',6diamidino-2-phenylindole; DPI, diphenyliodonium; EGCG, epigallocatechin gallate; FITC, fluorescein isothiocyanate; GAPDH, glyceraldehyde-3 phosphate dehydrogenase; $\mathrm{H}_{2}$ DCFDA, 2,7-dichlorodihydrofluorescein diacetate; $\mathrm{H}_{2} \mathrm{O}_{2}$, hydrogen peroxide; HO-1, heme oxygenase-1; IFN- $\gamma$, interferon-gamma; IMIED, immune-mediated inner ear disease; iNOS, inducible nitric oxide synthetase; IL-1 $\beta$, interleukin-1 $\beta$; JAK2, Janus kinase-2; L-NAME, $N_{\omega}$-nitro-L-arginine methyl ester; MAPK, mitogen-activated protein kinases; NOX3, nicotinamide adenine dinucleotide phosphate oxidase 3; Nrf2, NF-E2-related factor 2; NF- $\kappa$ B, nuclear factor- $\kappa$ B; OHC, outer hair cell; p-STAT1, phosphorylated STAT1; PCR, polymerase chain reaction; SL, spiral ligament; ROS, reactive oxygen species; Ser ${ }^{727}$, serine 727; siRNA, short interfering RNA; STAT1, signal transducer and activator of transcription-1; SG, spiral ganglion; SVA, stria vascularis; TACE, TNF- $\alpha$ converting enzyme; TNF- $\alpha$, tumor necrosis factor-alpha; TRAIL, TNF-related apoptosis inducing ligand; TRPV1, transient receptor vanilloid-1; Tyr ${ }^{701}$, tyrosine 701; XPA, xeroderma pigmentosium A Received 19.1.11; revised 01.6.11; accepted 01.6.11; Edited by A Stephanou
} 
Various transcription factors have been linked to cisplatinmediated inflammation in the cochlea. Inducible nitric oxide synthase (iNOS), a mediator of inflammation, is induced through nuclear factor $-\kappa \mathrm{B}(\mathrm{NF}-\kappa \mathrm{B})$ and is associated with damage to the cochlea. ${ }^{10}$ Activation of NF- $\kappa \mathrm{B}$ and activator protein-1 (AP-1) increased cytokine expression and apoptosis in the cochlea and in immortalized cochlear cells derived from the organ of Corti. ${ }^{11}$ Signal transducer and activator of transcription-1 (STAT1) is also implicated in cisplatin-induced apoptosis of mouse utricular hair cells in vitro. ${ }^{12}$ However, it is still unclear whether STAT1 mediates damage to OHCs in cisplatin-induced hearing loss.

STAT1 is a cytoplasmic transcription factor involved in signaling cascades initiated by cytokines and cellular stress. These signals promote the phosphorylation of STATs in the cytoplasm on tyrosine $701\left(\mathrm{Tyr}^{701}\right)$ and serine $727\left(\mathrm{Ser}^{727}\right)$. STAT1 then translocates to the nucleus, where it regulates genes involved in inflammation, such as iNOS, ${ }^{13}$ cyclooxygenase-2 (COX-2) ${ }^{14}$ and TNF- $\alpha,{ }^{15}$ and genes linked to apoptosis, such as Fas, TNF-related apoptosis-inducing ligand (TRAIL) and caspases. ${ }^{16}$ STAT1 also mediates cell apoptosis by cisplatin in coordination with the cell-cycle regulator $\mathrm{p} 53 .{ }^{17}$ In fact, in some cell types, cisplatin activation of STAT 1 is absolutely dependent on p53, as it is not observed in p53-null cells. ${ }^{18}$

This study tests the hypothesis that STAT1 couples cisplatin-mediated ROS generation to inflammation in the cochlea, which produces hearing loss. We show that ROS generation through NOX3 is critical for cisplatin-induced $\mathrm{Ser}^{727}$ phosphorylation of STAT1 in cultured organ of Corti hair cells (UB/OC-1) and rat cochlea. Knockdown of STAT1 inhibited cisplatin-induced inflammation and apoptosis, and protected against ototoxicity. Furthermore, inhibition of TNF- $\alpha$ by etanercept reduced the damage and loss of OHCs, and attenuated cisplatin ototoxicity. These data support an essential role of STAT1 in mediating cisplatin ototoxicity.

\section{Results}

Cisplatin increases STAT1 activity in UB/OC-1 cells and rat cochlea. UB/OC-1 cells exposed to cisplatin $(2.5 \mu \mathrm{M})$ for up to $120 \mathrm{~min}$ indicated increased $\mathrm{Ser}^{727}$-phosphorylated STAT1 (p-STAT1). The levels of p-STAT1 peaked in $45 \mathrm{~min}$ and remained elevated for at least $120 \mathrm{~min}$ (Figure 1a). STAT1 activation was dose-dependent with cisplatin concentrations from 2.5 to $10 \mu \mathrm{M}$ (Supplementary Figure $1 \mathrm{~A}$ ). Cisplatin at $2.5 \mu \mathrm{M}$ was chosen for future experiments because this dose promotes STAT1 activation and closely estimates the clinical plasma concentrations of cisplatin. ${ }^{19}$ Exposure to $50 \mu \mathrm{M}$ epigallocatechin gallate (EGCG), a STAT1 inhibitor, ${ }^{20}$ reduced cisplatin-induced $p$-STAT1 (Supplementary Figure 1B). Cisplatin did not produce any STAT1 Tyr $^{701}$ phosphorylation, assessed over a period of $8 \mathrm{~h}$, in contrast with increased $\mathrm{Tyr}^{701} \mathrm{p}$-STAT1 induced by interferon-gamma (IFN- $\gamma$ ) (Supplementary Figure 1C). Cisplatin also increased STAT1 luciferase activity, which peaked by $8 \mathrm{~h}$ and returned to baseline by $12 \mathrm{~h}$ (Supplementary Figure 1D). Cisplatin-increased STAT1 luciferase activity was attenuated by incubation with EGCG
$(50 \mu \mathrm{M})$ (Supplementary Figure 1E) or by STAT1 short interfering RNA (siRNA) (Figure 1c). As anticipated, IFN- $\gamma$ significantly increased STAT1 luciferase activity 10.2 $\pm 0.7-$ fold (mean \pm S.E.M.) (Supplementary Figure $1 \mathrm{~F}$ ), a fold greater than that observed with cisplatin, which averaged $4.8 \pm 0.4$-fold (Supplementary Figure 1F).

Incubation of UB/OC-1 cells with 10 nM STAT1 siRNA for $48 \mathrm{~h}$ reduced the basal STAT1 protein by $70 \pm 13 \%$ (Figure $1 \mathrm{~b}$ ) and STAT1 mRNA by $\sim 90 \%$ (Supplementary Figure $1 \mathrm{H}$ ), indicating effective knockdown of STAT1. STAT1 SiRNA reduced basal and cisplatin-stimulated $\mathrm{Ser}^{727}$ $\mathrm{p}$-STAT1 activity without altering the levels of $\beta$-actin, used to ensure equal loading of the proteins (Figure 1b). STAT1 siRNA also reduced the basal and IFN- $\gamma$-stimulated $\mathrm{Ser}^{727}$ p-STAT1 activity by $85 \pm 0.84 \%$ in the UB/OC-1 cells (Supplementary Figure 1I), indicating that STAT1 is a downstream effector of cisplatin. Scramble siRNA does not affect p-STAT1 activity, compared with cells not administered siRNA, indicating that the transfection process did not produce stress to the cells (Supplementary Figure 1G).

Cisplatin increased nuclear translocation of STAT1, as indicated by $4^{\prime}, 6$-diamidino-2-phenylindole (DAPI, nuclear stain) and $\operatorname{Ser}^{727}$ p-STAT1 immunolabeling. DAPI-stained nuclei were deep blue to purple in all the treatment groups examined. Nuclear p-STAT1 labeling (green) was more intense in the cisplatin-treated cells as compared with scramble siRNA- or STAT1 siRNA + cisplatin-treated cells. STAT1 nuclear translocation is also indicated by color differences in the merged images, which changed from deep blue/purple in the scramble siRNA group and the scramble siRNA + cisplatin group to light blue/green in the scramble siRNA + cisplatin group (Supplementary Figure 2A). STAT1 siRNA produced significant knockdown of STAT1 in UB/OC-1 cells (Supplementary Figure 2B).

STAT1 siRNA reduced STAT1 immunolabeling in the rat cochlea when administered by the trans-tympanic route followed by intraperitoneal (i.p.) administration of vehicle or cisplatin $(11 \mathrm{mg} / \mathrm{kg}) 2$ days later. Low baseline p-STAT1 immunoreactivity was observed in the cochleae from rats administered scramble siRNA alone, which were reduced by STAT1 siRNA. Cisplatin increased p-STAT1 immunoreactivity in the cochleae, which was reduced by trans-tympanic STAT1 siRNA (Figure 1d). Increases in p-STAT1 immunoreactivity were observed in the OHCs, stria vascularis (SVA), SL and spiral ganglion (SG) cells. Trans-tympanic administration of siRNA to rats reduced the p-STAT1 immunoreactivity in these regions (Figure 1d). p-STAT1 immunolabeling redistributed from the cytoplasm to the nucleus in OHCs following administration of cisplatin (Figure 1e). Nuclear distribution of p-STAT1 in the OHCs was reduced by STAT1 siRNA pretreatment (Figure 1e). STAT1 knockdown in the cochlea is demonstrated by immunofluorescent labeling (Supplementary Figures $3 \mathrm{~A}$ and $\mathrm{B}$ ) and confirmed by real-time polymerase chain reaction (PCR) determination of STAT1 mRNA (Supplementary Figure $3 \mathrm{C}$ ).

Cisplatin-induced STAT1 activation involves ROS generation through NOX3 NADPH oxidase. Cisplatin ototoxicity is mediated, in part, by ROS produced through NOX3., ${ }^{2,3}$ ROS regulates STAT1 phosphorylation in pancreatic cancer cells by maintaining Janus kinase- 2 
a

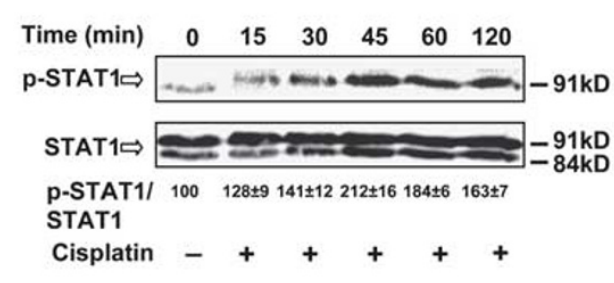

b

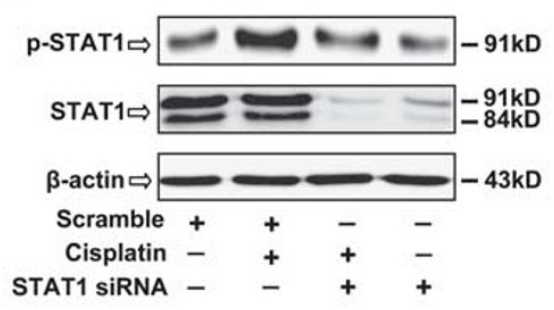

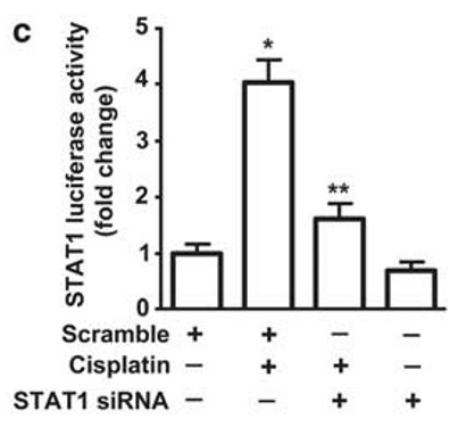
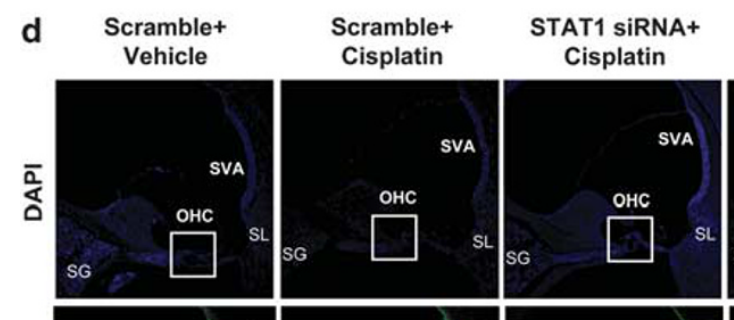

STAT1 SIRNA+ Vehicle
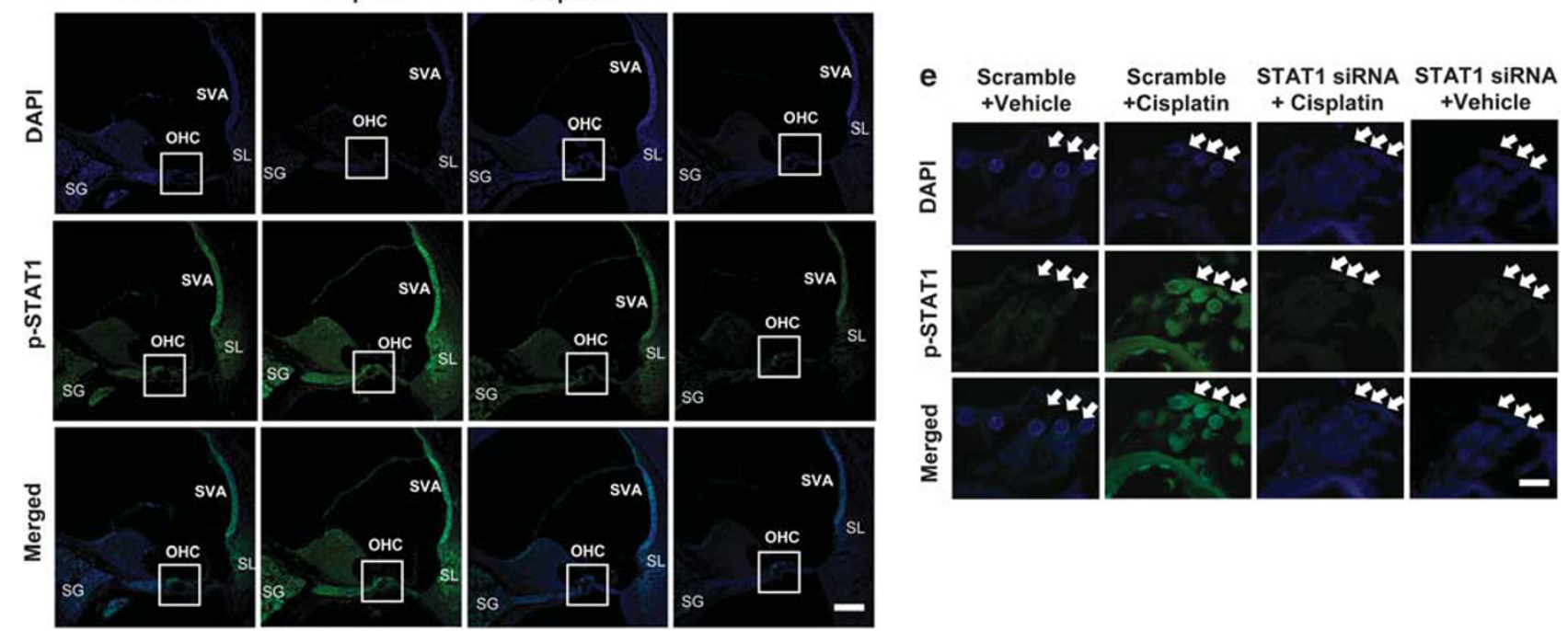

Figure 1 Cisplatin activates STAT1 in UB/OC-1 cells and in the rat cochlea. (a) UB/OC-1 cells were treated with $2.5 \mu \mathrm{M}$ cisplatin for different time periods and STAT1 activation was determined by western blotting of whole-cell lysates. Activation of STAT1 (p-STAT1/STAT1) is indicated below. (b) UB/OC-1 cells were transfected with scramble siRNA or STAT1 siRNA for $48 \mathrm{~h}$ before cisplatin treatment for $45 \mathrm{~min}$. Cell lysates were prepared and used in western blot studies for Ser ${ }^{727} \mathrm{p}-\mathrm{STAT1}$. (c) UB/OC-1 cells were co-transfected with a plasmid vector encoding STAT1 luciferase, along with a scramble or STAT1 siRNA. This was followed $24 \mathrm{~h}$ later with vehicle or cisplatin $(2.5 \mu \mathrm{M})$ for $8 \mathrm{~h}$. Lysates were prepared and used for determination of luciferase activity. Co-transfection of a plasmid expressing Renilla luciferase allows normalization of luciferase activity in each well. (d) Immunolabeling studies were performed on the cochlear sections isolated from rats treated with vehicle or cisplatin $(11 \mathrm{mg} / \mathrm{kg}$, i.p.) for $72 \mathrm{~h}$ following trans-tympanic administration of scramble or STAT1 siRNA $(0.9 \mu \mathrm{g})$. Ser ${ }^{727}$ p-STAT1 immunolabeling is indicated by green fluorescence whereas cell nuclei are defined by DAPI staining as indicated. Increased immunofluorescence is observed in the OHC, SVA, SG cells and SL. The scale bar shown in the lower right panel measures $50 \mu \mathrm{m}$. (e) Magnified view of the OHC from panel d. The arrows indicate the three rows of OHCs. The scale bar shown in the lower right panel measures $10 \mu \mathrm{m}$. Data are presented as mean \pm S.E.M. The asterisks $\left({ }^{*}\right)$ and $\left({ }^{* *}\right)$ denote statistically significant difference from the vehicle/scramble- and the scramble + cisplatin-treated group, respectively $(P<0.05, n=3)$

(JAK2) in a constitutively active state. ${ }^{21}$ We show that cisplatin-increased $\mathrm{p}$-STAT1 was reduced by inhibiting NADPH oxidase with diphenyliodonium (DPI), implicating ROS in STAT1 activation in the cochlea. Furthermore, hydrogen peroxide $\left(\mathrm{H}_{2} \mathrm{O}_{2}, 50 \mu \mathrm{M}\right)$ increased p-STAT1 in UB/OC-1 cells (Figure 2a). In addition, knockdown of NOX3 by siRNA inhibited cisplatin-induced STAT1 activation (Figure $2 \mathrm{~b}$ ). We routinely obtained $>50 \%$ knockdown of NOX3 expression by siRNA in UB/OC-1 cultures (Figure 2c), which resulted in reduced cisplatin-induced ROS generation (Figure 2d). Thus, NOX3 contributes significantly to cisplatinmediated ROS generation in UB/OC-1 cells. Trans-tympanic administration of NOX3 siRNA was shown to reduce NOX3 expression in the cochlea. ${ }^{4}$ Cochlea excised from rats administered NOX3 siRNA trans-tympanically showed reduced cisplatin-induced p-STAT1 levels (Supplementary Figure 4). Overall, these data support a role of ROS generation (through NOX3) in the activation of STAT1 in the cochlea.
STAT1 mediates cisplatin-induced apoptosis. Treatment of UB/OC-1 cells with cisplatin has been shown to increase cell apoptosis. ${ }^{3}$ To test the role of STAT1 activation in mediating this process, cells were transfected with a scramble or STAT1 siRNA prior to cisplatin administration. Minimal cell death $(\sim 7 \%)$ was produced by the scramble sequence (Figures $3 a$ and b). Cisplatin increased UB/OC-1 cell apoptosis by $\sim 30 \%$, which was abolished by STAT1 siRNA (Figures $3 a$ and b), implicating STAT1 in cisplatininduced apoptosis. Cisplatin-induced p53, caspase-3 and Bax proteins were abolished by STAT1 siRNA (Figures $3 \mathrm{c}$ and d). Similarly, cisplatin-induced Bax and downregulation of Bcl2 expression were abrogated by STAT1 siRNA (Supplementary Figure 5).

STAT1 siRNA reduced cisplatin-induced hearing loss and damage to OHCs. Rats were treated with a scramble or STAT1 siRNA by trans-tympanic injection, followed by cisplatin 2 days later. Auditory brainstem responses (ABRs) 
a

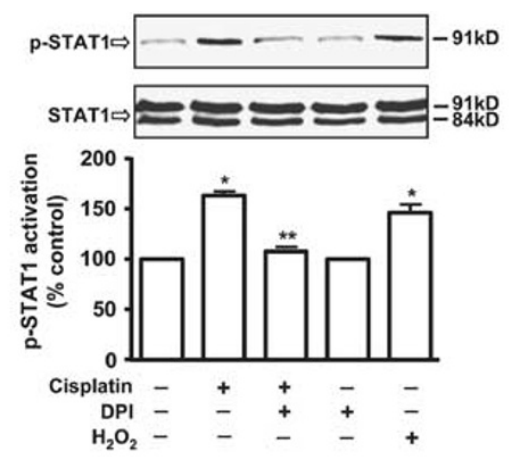

c

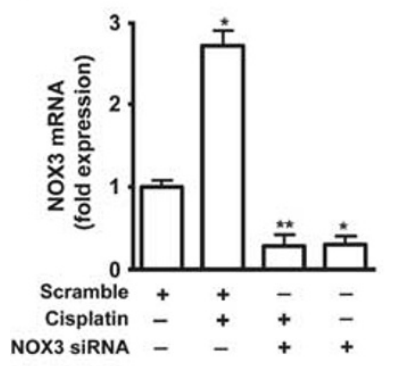

d Scramble + Vehicle

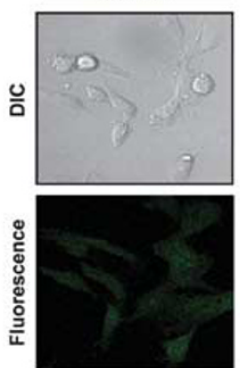

b
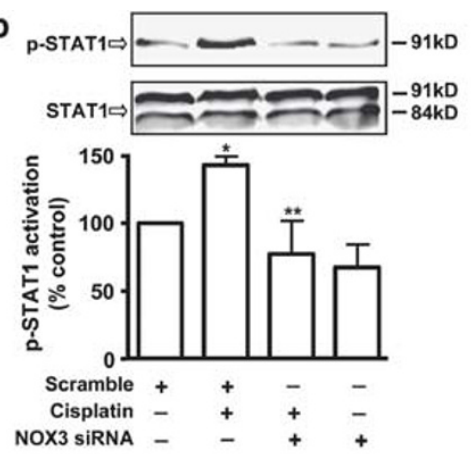

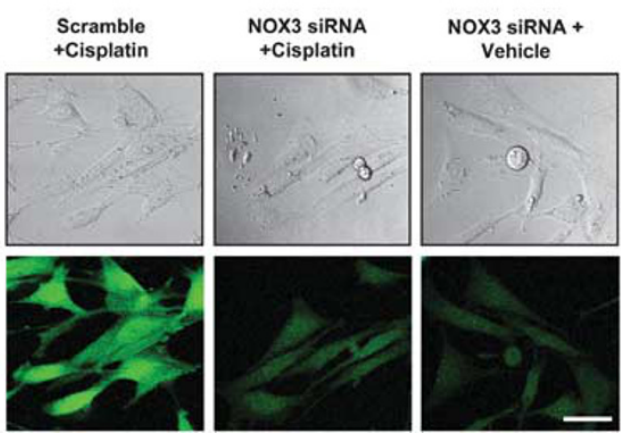

Figure 2 ROS are essential for cisplatin-mediated STAT1 phosphorylation. (a) UB/OC-1 cells were pre-treated with vehicle or DPI (10 $\mu \mathrm{M})$, followed by cisplatin treatment for $45 \mathrm{~min}$. STAT1 activation was determined by western blotting. $\mathrm{H}_{2} \mathrm{O}_{2}(100 \mu \mathrm{M})$ treatment served as the positive control for ROS generation. (b) Cells were transfected with scramble or NOX3 siRNA $(5 \mathrm{nM})$ for $48 \mathrm{~h}$, the culture media was replaced with fresh media and cells were exposed to vehicle or cisplatin $(2.5 \mu \mathrm{M})$ for $45 \mathrm{~min}$. NOX3 siRNA blunted the activation of STAT1 by cisplatin without altering basal STAT1 levels. (c) UB/OC-1 cells were transfected with either scramble or NOX3 siRNA (5 nM) for $48 \mathrm{~h}$, followed by cisplatin $(2.5 \mu \mathrm{M})$ treatment for another $24 \mathrm{~h}$. NOX3 mRNA, measured by real-time RT-PCR, showed a $2.7 \pm 0.2$-fold increase by cisplatin, which was reduced to $0.3 \pm 0.1$-fold in the NOX3 siRNA + cisplatin group. NOX3 siRNA added alone reduced NOX3 mRNA to $0.3 \pm 0.1$-fold. (d) ROS generation was measured in UB/OC-1 cells transfected with either scramble or NOX3 siRNA $(5 \mathrm{nM})$ for $48 \mathrm{~h}$, followed by treatment with cisplatin $(2.5 \mu \mathrm{M})$ for 15 min. Cells were then incubated with $5 \mu \mathrm{M} \mathrm{H} \mathrm{H}_{2} \mathrm{DCFDA}$ dye for $15 \mathrm{~min}$ and ROS generation (green fluorescence) was visualized by confocal microscopy. DIC, differential interference contrast. Data are presented as mean \pm S.E.M. The asterisks $\left({ }^{*}\right)$ and $\left({ }^{*}\right)$ denote statistically significant difference from the vehicle/scramble- and the scramble + cisplatin-treated group, respectively $(P<0.05, n=4)$. The scale bar shown measures $10 \mu \mathrm{m}$

were assessed before and 3 days following cisplatin administration. Scramble siRNA produced minimal change in $A B R$ thresholds from pre-treatment values. Cisplatin elevated $A B R$ thresholds, which averaged $25 \pm 3,35 \pm 5$ and $42 \pm 4$ decibels (dB), at frequencies of 8,16 and $32 \mathrm{kHz}$, respectively. STAT1 siRNA significantly attenuated cisplatininduced hearing loss $(P<0.05, n=6)$ (Figure 4a). Cochleae obtained from animals treated with STAT1 siRNA alone showed no damage in OHC morphology, but reduced cisplatin-induced damage assessed by scanning electron microscopy at the base of the cochlea (Figure 4b), as indicated by arrows. A $75 \pm 6 \%$ destruction or loss of OHCs was observed with cisplatin, which was attenuated by STAT1 siRNA (Figure 4c).

STAT1 mediates cisplatin-induced inflammation. STAT1 regulates a number of genes involved in inflammation, such as iNOS, ${ }^{13}$ COX- $-2^{14}$ and TNF- $\alpha,{ }^{15}$ which are implicated in ototoxicity. ${ }^{22-24}$ Cisplatin $(2.5 \mu \mathrm{M})$ increased the levels of COX-2, iNOS and TNF- $\alpha$ proteins in UB/OC-1 cells, which were suppressed by STAT1 siRNA (Figures $5 \mathrm{a}-\mathrm{C}$ ). TNF- $\alpha$ levels were $133 \pm 9 \%, 92 \pm 5 \%$ and $72 \pm 9 \%$ of scramble siRNA control cells for the cisplatin, the STAT1 siRNA + cisplatin and the STAT1 siRNA group, respectively. iNOS levels were $172 \pm 5 \%, 104 \pm 2 \%$ and
$100 \pm 1 \%$ of scramble siRNA controls for the cisplatin, the STAT1 siRNA + cisplatin and the STAT1 siRNA group, respectively. In addition, COX-2 levels were $192 \pm 5 \%$, $95 \pm 10 \%$ and $100 \pm 1 \%$ for the respective groups. Similar changes were also observed in the expression of their genes (Figure 5d). The respective TNF- $\alpha$ expressions were $2.2 \pm 0.4,0.4 \pm 0.1$ and $0.2 \pm 0.1$-fold of control cells treated with scramble siRNA. The respective iNOS expressions were $2.6 \pm 0.1,1.1 \pm 0.1$ and $1.0 \pm 0.1$-fold of control cells treated with scramble siRNA, whereas those of COX-2 expression for these groups were $4.5 \pm 0.1,1.8 \pm 0.1$ and $1 \pm 0.1$-fold. Interestingly, STAT1 siRNA suppressed the basal levels of TNF- $\alpha$ mRNA and protein, but did not affect the basal levels of iNOS or COX-2, suggesting differences in the regulation of these genes by STAT1. These data implicate STAT1 in mediating cisplatin-induced inflammation in vitro.

To determine whether cisplatin induces inflammation in vivo, we monitored the levels of TNF- $\alpha$ and CD14 in the cochlea. CD14 immunolabeling serves as a marker for immune cells infiltration ${ }^{25}$ into the cochlea. Immunolabeling of TNF- $\alpha$ and CD14 was observed in the SVA, SL, spiral limbus, SG and OHCs in animals treated trans-tympanically with scramble or STAT1 siRNA. These proteins were colocalized, based on merged images. Cisplatin increased the immunolabeling of these proteins at all of these sites. 

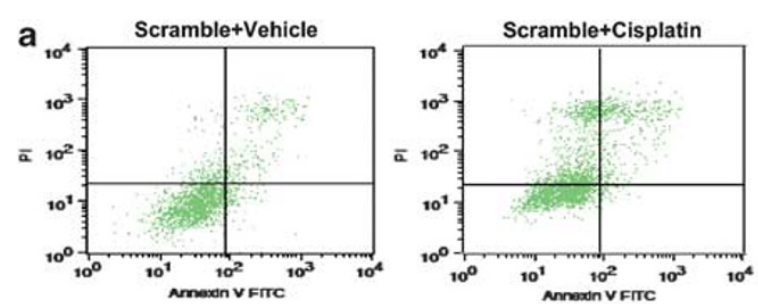

b
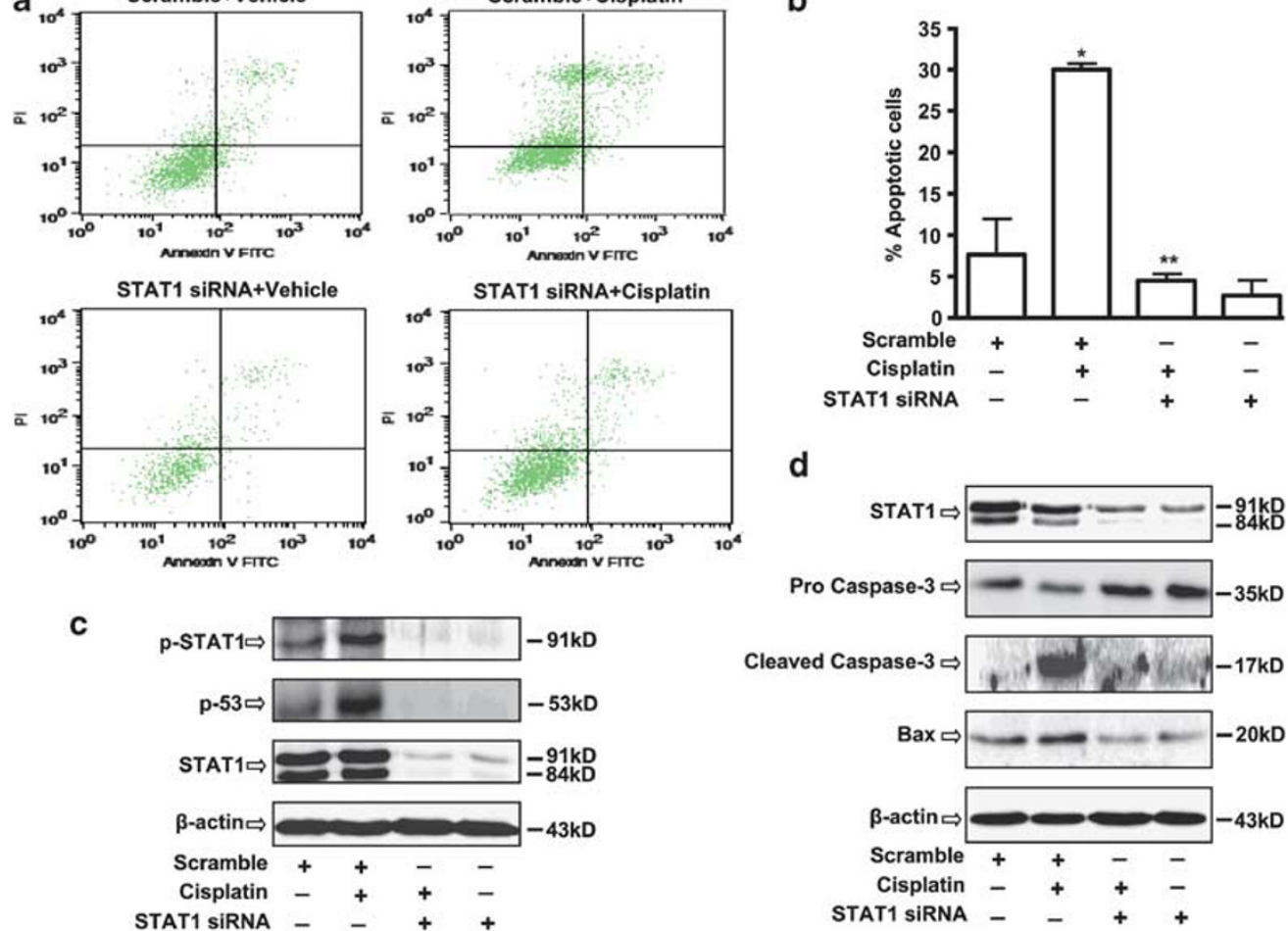

Figure 3 STAT1 siRNA reduced the cisplatin-mediated apoptosis of UB/OC-1 cells. (a) UB/OC-1 cells were transfected with scramble or STAT1 siRNA for $48 \mathrm{~h}$, followed by cisplatin $(20 \mu \mathrm{M})$ for an additional $24 \mathrm{~h}$. Apoptosis was determined by measuring the percentage of Annexin-positive and Annexin plus propidium iodide-positive cells (lower right and upper right quadrant respectively) by flow cytometry. (b) Percentage of apoptotic cells for each treatment as determined in panel a and plotted as the mean \pm S.E.M. $\left({ }^{*} P<0.05, n=3\right)$. (c and d) UB/OC-1 cells were transfected with scramble or STAT1 siRNA for $48 \mathrm{~h}$, followed by cisplatin $(20 \mu \mathrm{M})$ for an additional $24 \mathrm{~h}$. (c) Cells were used to determine the levels of p53, p-STAT1, STAT1 and $\beta$-actin (for normalization). (d) Cisplatin increased the levels of Bax and cleaved caspase-3, which were attenuated by STAT1 siRNA. The figure shown is representative of four similar experiments showing similar results. Data are presented as mean \pm S.E.M. The asterisks $\left({ }^{*}\right)$ and $\left({ }^{* *}\right)$ indicate statistically significant difference from the scramble siRNA group or the cisplatin-treated group, respectively $(P<0.05)$

However, trans-tympanic STAT1 siRNA suppressed the increases in these inflammatory markers (Figures $6 a$ and $b$ ), implicating STAT1 in the induction of TNF- $\alpha$ and CD14 in vivo, and suggesting colocalization of both of these proteins in cochlear cells. Additional studies also indicated significant coregulation of both TNF- $\alpha$ and $\operatorname{Ser}^{727}$ p-STAT, especially following cisplatin administration (Supplementary Figure 6). These data implicate STAT1 in the induction of both TNF- $\alpha$ and CD14 in the cochlea by cisplatin. Similarly, we observed an induction in the expression of TNF- $\alpha, C O X-2$ and iNOS (Supplementary Figures $7 \mathrm{~A}-\mathrm{C}$ ) by cisplatin in the cochlea, which were reduced by STAT1 siRNA. These data implicate STAT1 in mediating cisplatin-induced cochlear inflammation in vivo.

The intensity of labeling suggests that CD14 and TNF- $\alpha$ could be expressed by normal cells in the cochlea, in addition to resident immune cells and those recruited from the circulation. We demonstrated a similar pattern of co-labeling for CD45, a known marker for immune cells, and TNF- $\alpha$ (Supplementary Figure 8). Furthermore, increased CD14 and CD45 fluorescent labeling was observed in UB/OC-1 cells treated with cisplatin, as assessed by flow cytometry (Supplementary Figure 9). These data may indicate that resident cells in the cochlea, such as $\mathrm{OHCs}$, can produce immune cell markers (such as CD14, CD45) and cytokines (such as TNF- $\alpha$ ) upon stimulation by oxidative stress or cytokines.
Suppression of inflammatory mediators reduces cisplatin-mediated apoptosis. The significance of iNOS, COX-2 and TNF- $\alpha$ in mediating cisplatin-induced apoptosis was evaluated by using inhibitors of these proteins in UB/OC-1 cells. Apoptosis, measured by Annexin-V-fluorescein isothiocyanate (FITC) labeling, indicated a small but significant increase in apoptotic cells to $11 \pm 1 \%$ produced by incubation of cells with TNF- $\alpha(100 \mathrm{ng} / \mathrm{ml})$. TNF- $\alpha$ antibody reduced TNF- $\alpha$-mediated apoptosis (Figure 7a). TNF- $\alpha$ increased the levels of Bax, cleaved caspase- 9 and cleaved caspase- 3 , which were reduced by the TNF- $\alpha$ antibody (Figure 7b). Treatment of UB/OC-1 cells with cisplatin $(20 \mu \mathrm{M})$ produced $30 \pm 2 \%$ apoptotic cell death, which was reduced by pretreatment with the TNF- $\alpha$ antibody to $7 \pm 1 \%$ (Figure $7 \mathrm{C}$ ). These data are consistent with a role of TNF- $\alpha$ in cisplatin-mediated apoptosis in vitro.

Pretreatment of UB/OC-1 cells with $1 \mathrm{mM} N_{\omega}$-nitro-Larginine methyl ester hydrochloride (L-NAME, a nonselective inhibitor of iNOS) ${ }^{21}$ or $10 \mu \mathrm{M} \mathrm{SC791} \mathrm{(a} \mathrm{COX-2} \mathrm{inhibitor)}$ reduced cisplatin-mediated apoptosis. The basal levels of apoptosis were less than $1 \%$, whereas cisplatin-mediated apoptosis was observed in $38 \pm 2 \%$ of cells. Pretreatment with L-NAME or SC791 reduced apoptosis to $17 \pm 2 \%$ and $19 \pm 2 \%$, respectively (Figure $7 d$ ). These data are consistent with roles of iNOS and COX-2 in mediating cisplatin ototoxicity. 

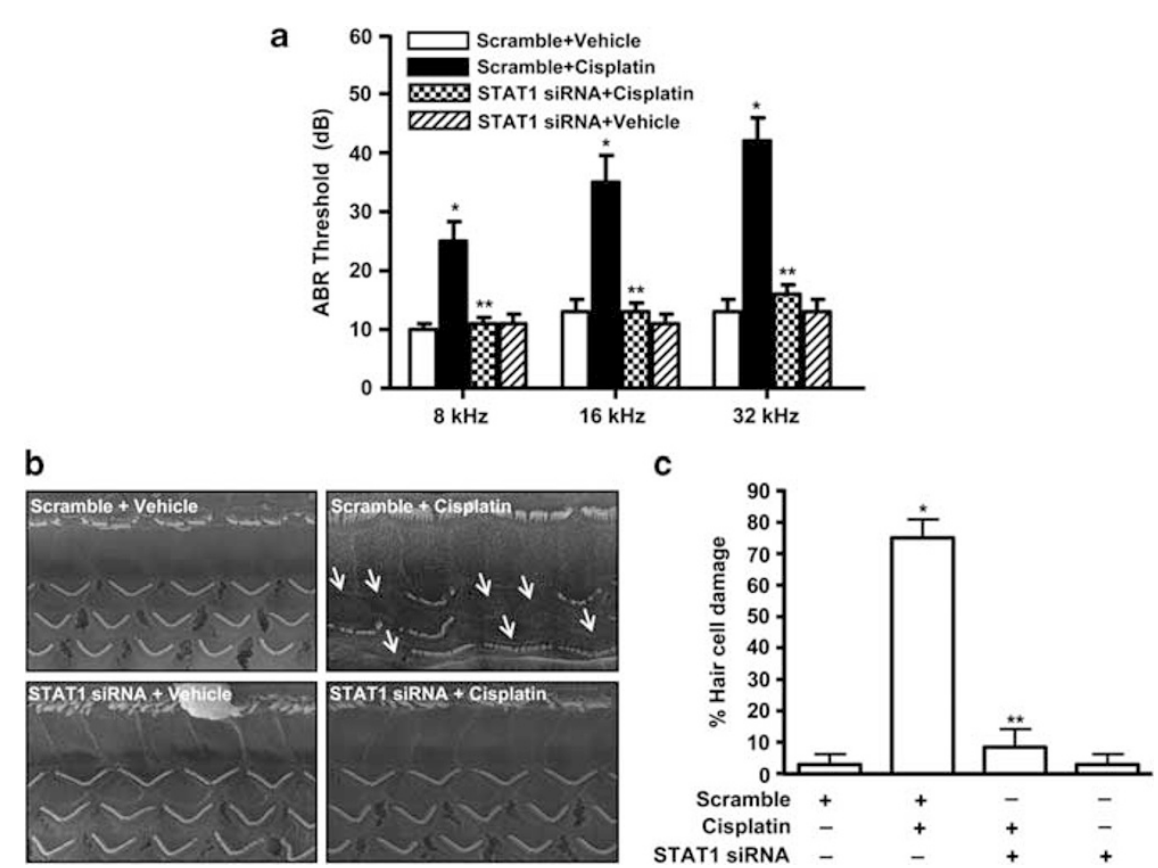

Figure 4 Cisplatin-induced hearing loss in rats is dependent on STAT1 activation. (a) ABR thresholds were recorded in Wistar rats treated with cisplatin (11 mg/kg, i.p.) for $72 \mathrm{~h}$ following $48 \mathrm{~h}$ trans-tympanic administration of scramble or STAT1 siRNA $(0.9 \mu \mathrm{g})$. (b) Scanning electron microscopic studies were performed on the cochleae. The representative image shows significant damage to OHCs (white arrows) by cisplatin, which is absent in the presence of STAT1 siRNA. (c) Quantitative analysis of the scanning electron micrographs. Data are presented as mean \pm S.E.M. The asterisks $\left({ }^{*}\right)$ and $\left({ }^{*}\right)$ indicate statistically significant difference from the scramble or the scramble + cisplatin treatment group $(P<0.05, n=6)$

a
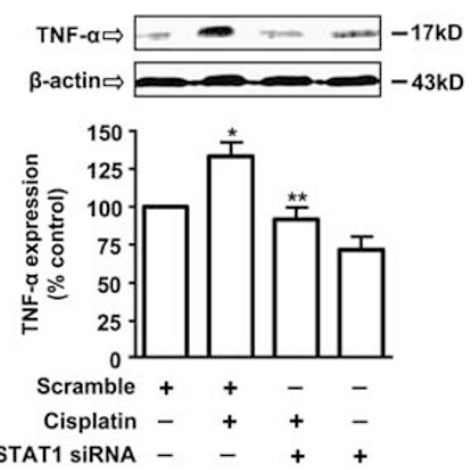

C
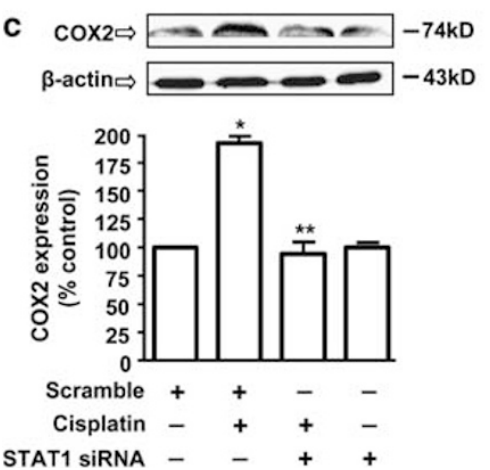

d b iNOS $\Leftrightarrow \longrightarrow-130 \mathrm{kD}$

$\beta$-actin $\Rightarrow-43 \mathrm{kD}$

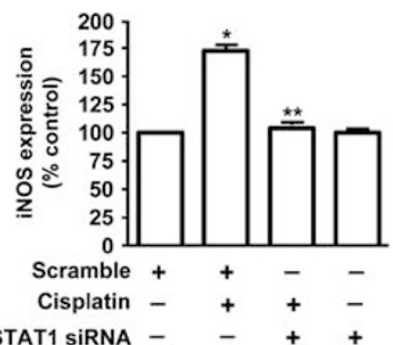

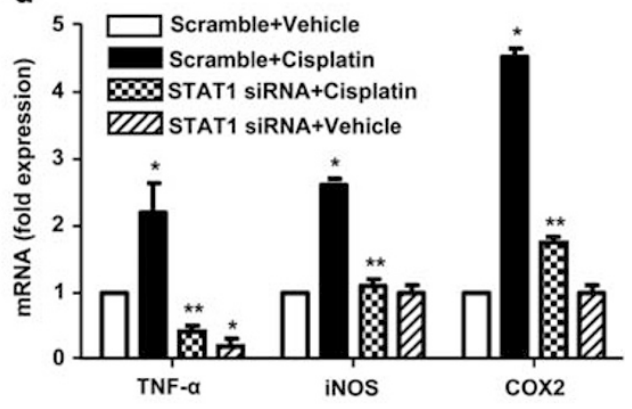

Figure 5 Cisplatin increases the expression and transcription of pro-inflammatory mediators through the STAT1-dependent pathway. (a-c) UB/OC-1 cells were transfected with scramble or STAT1 siRNA for $48 \mathrm{~h}$, followed by cisplatin $(2.5 \mu \mathrm{M})$ for $24 \mathrm{~h}$. Cell lysates were then used for western blotting studies to determine the levels of TNF- $\alpha$ (a), iNOS (b) and COX2 (c). $\beta$-Actin levels were used for normalization. (d) mRNA levels of iNOS, COX2 and TNF- $\alpha$ were determined by real-time RT-PCR in UB/OC-1 cultures treated as described in panels a-c. Data are presented as mean \pm S.E.M. The asterisks $\left(^{*}\right)$ and $\left(^{* *}\right)$ denote statistically significant difference from the scramble- and the scramble + cisplatin-treated group, respectively $(P<0.05, n=4)$ 

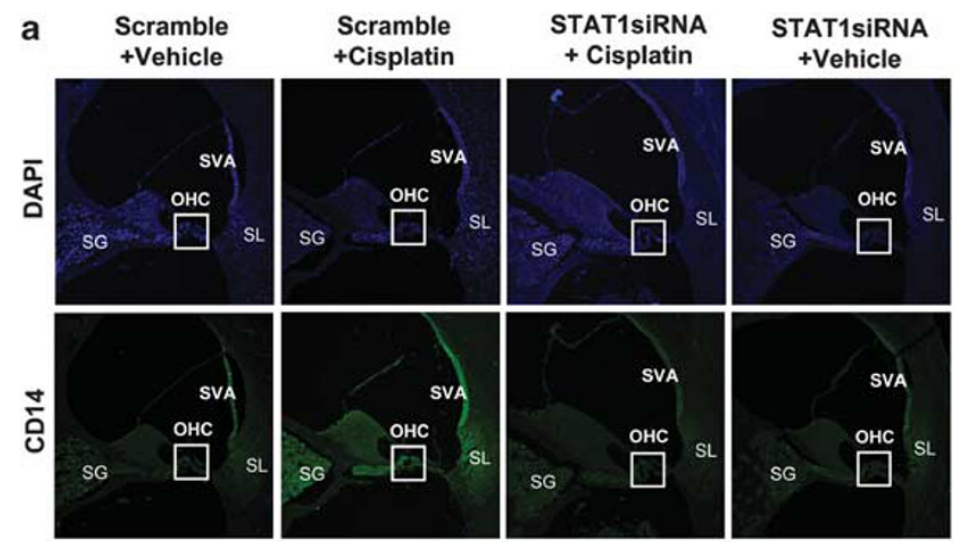

b
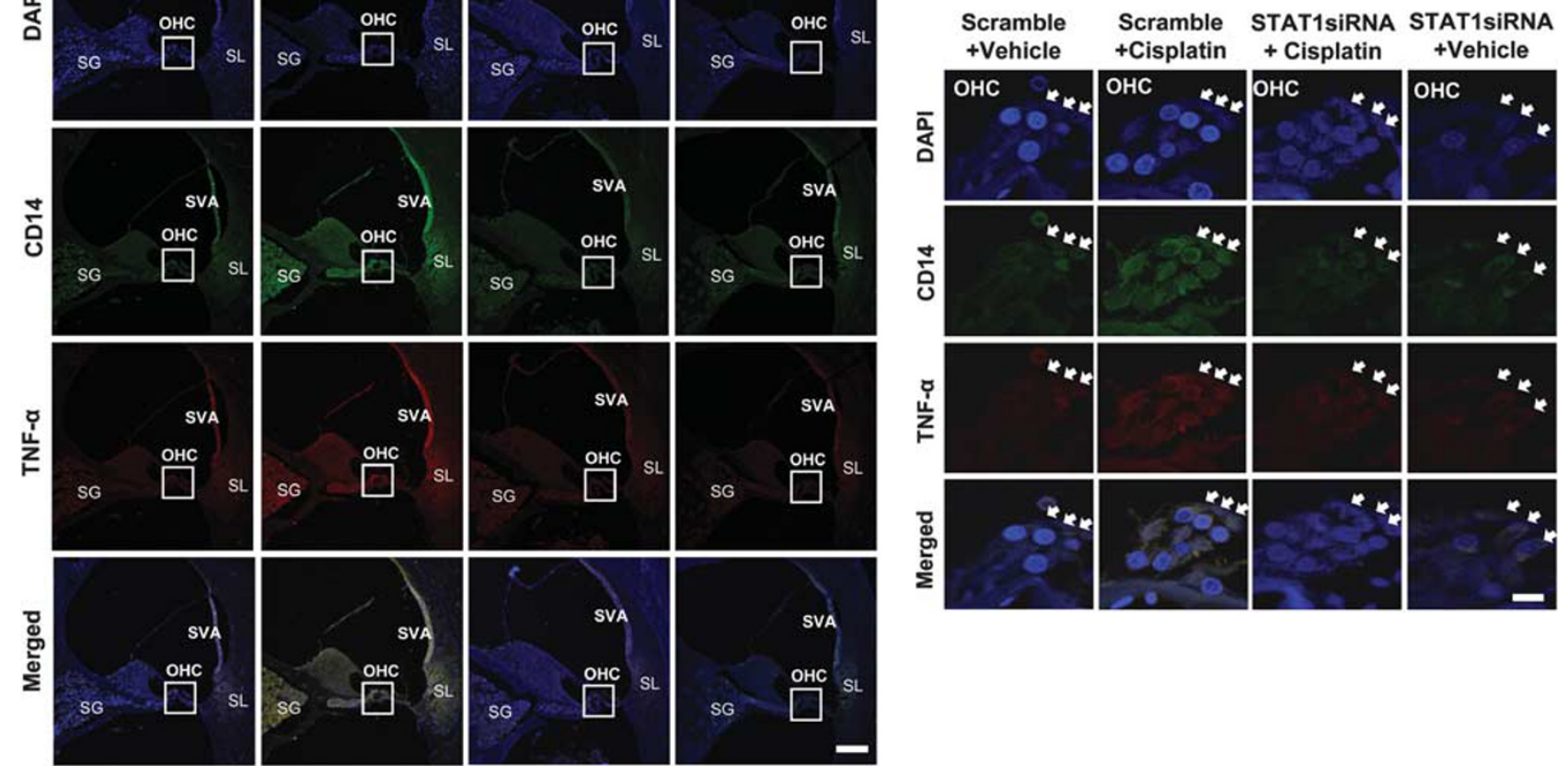

Figure 6 Cisplatin increases inflammation in rat cochlea. (a) Rats were treated with scramble or STAT1 siRNA by trans-tympanic injections followed by vehicle or cisplatin $(11 \mathrm{mg} / \mathrm{kg}$, i.p.) $48 \mathrm{~h}$ later. The rats were killed $72 \mathrm{~h}$ following the administration of vehicle or cisplatin. The cochleae were excised and processed for immunohistochemistry. Mid-modiolar sections of the cochlea were co-labeled with CD14 and TNF- $\alpha$ antibodies, followed by fluorescein- (green) or TRITC (red)-labeled secondary antibodies. Cisplatin increased CD14 and TNF- $\alpha$ immunoreactivity in cochleae treated with scramble siRNA. However, the increases in immunolabeling were attenuated in cochlea pretreated with STAT1 siRNA. The merged panels (yellow) indicate colocalization of CD14 and TNF- $\alpha$. The scale bars (right lower panel) indicate $50 \mu \mathrm{m}$. (b) Magnified view of the OHCs presented in panel a. The arrows indicate three rows of OHCs. The scale bar indicates $10 \mu \mathrm{m}$

Inhibition of TNF- $\alpha$ by etanercept protects against cisplatin-induced ototoxicity. To determine the relevance of TNF- $\alpha$ to cisplatin ototoxicity in vivo, rats were administered vehicle or etanercept $(250 \mu \mathrm{g} / 50 \mu \mathrm{l}$ per ear) by the transtympanic route, followed by cisplatin $(11 \mathrm{mg} / \mathrm{kg}$, i.p.). Hearing thresholds were assessed 3 days later. Cisplatin significantly increased ABR thresholds, assessed at 8-, 16- and 32-kHz frequencies (Figure $8 \mathrm{a}$ ), which were significantly reduced by trans-tympanic etanercept. ABR threshold shifts were $32 \pm 4$, $33 \pm 4$ and $52 \pm 3 \mathrm{~dB}$, measured at 8,16 and $32 \mathrm{kHz}$, respectively, following cisplatin administration. Threshold shifts in the etanercept + cisplatin group were $12 \pm 2,12 \pm 2$ and $15 \pm 2 \mathrm{~dB}$, assessed at 8,16 and $32 \mathrm{kHz}$, respectively. Scanning electron micrograph images obtained from the cochleae of these rats show substantial damage or loss of OHCs (indicated by arrows) by cisplatin in the basal turn of the cochlea, but statistically significant protection with etanercept (Figure 8b). The percentage of $\mathrm{OHCs}$ showing damage or loss in the cochleae by cisplatin is shown in Figure 8c. Cisplatin produced damage or loss of $58 \pm 6 \%$ of OHCs, whereas pretreatment with etanercept significantly reduced this to $6 \pm 3 \%$ of OHCs. These data are consistent with the conclusion that etanercept protects against cisplatin-induced damage or loss of OHCs and are in agreement with measures of ABRs.

\section{Discussion}

The data presented in this paper implicate STAT1 in cisplatinmediated ototoxicity. STAT1 is rapidly activated by cisplatin through ROS generation by means of NOX3 NADPH oxidase. Knockdown of STAT1 by siRNA reduced apoptosis in UB/OC-1 cells and decreased cisplatin-mediated damage/loss of $\mathrm{OHC}$ in the rat organ of Corti. Downstream effectors of STAT1, such as TNF- $\alpha$, COX2 and iNOS, also contributed to cisplatin-induced apoptosis and ototoxicity. Furthermore, increases in these inflammatory mediators were associated with increased immune (CD14- and CD45-positive) cells in the cochlea. Importantly, inhibition of $\mathrm{TNF}-\alpha$ reduced cisplatin-induced ototoxicity. These data suggest that STAT1 couples ROS to inflammation in the cochlea and indicate that inhibition of this molecule or its downstream targets could ameliorate cisplatin ototoxicity.

Increased inflammatory markers induced by cisplatin were widely distributed in cochlear regions such as OHCs, SG, SVA, SL and spiral limbus. These markers showed diffused labeling, rather than more localized and discrete labeling, as would be anticipated from resident immune cells or the recruitment of circulating immune cells. This observation suggests that the resident, non-immune cells of the cochlea could be stimulated to produce inflammatory markers. The 

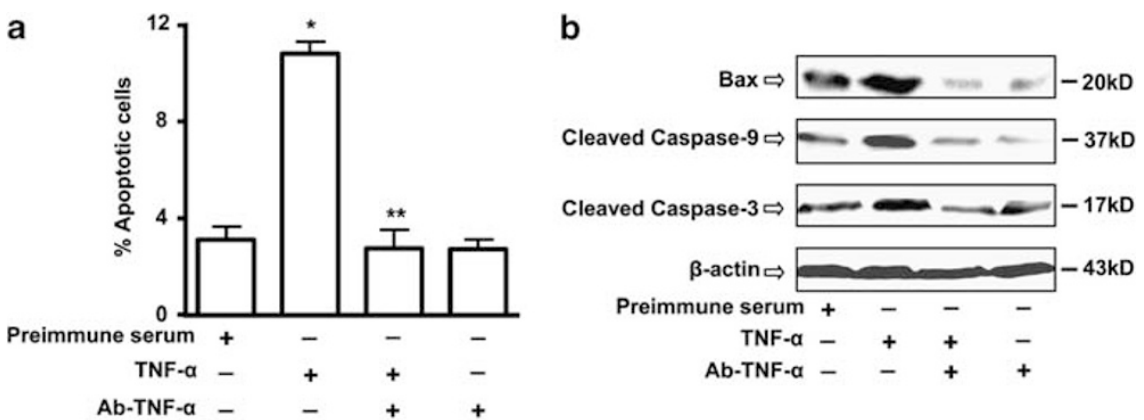

C

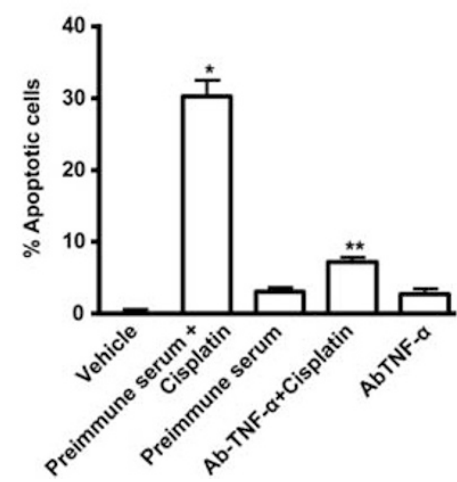

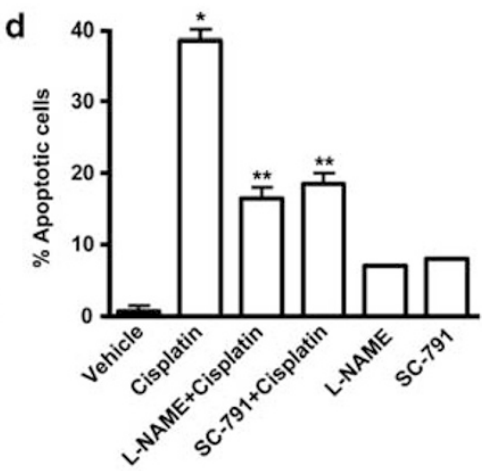

Figure 7 Role of inflammatory pathways in mediating cisplatin-induced hearing loss. (a) UB/OC-1 cells were pre-treated with pre-immune serum or a monoclonal antibody against TNF- $\alpha$, followed by addition of TNF- $\alpha$. The cells were harvested $24 \mathrm{~h}$ later and percent apoptosis was determined by Annexin-V-FITC staining by flow cytometry. TNF- $\alpha$ produced a significant increase $(P<0.05, n=4)$ in apoptosis, which was abrogated by the monoclonal antibody against TNF- $\alpha$. (b) Lysates prepared from cells treated as in panel a showed increased levels of Bax, cleaved caspase-9 and cleaved caspase- 3 by western blotting. Blots were normalized to $\beta$-actin. (c) UB/OC-1 cells were pretreated with vehicle (control), pre-immune serum or TNF- $\alpha$ antibody, followed by administration of vehicle or cisplatin ( $20 \mu \mathrm{M})$. Cisplatin increased the percentage of apoptotic cells in these groups by $24 \mathrm{~h}$, which was significantly reduced by the TNF- $\alpha$ monoclonal antibody $(P<0.05, n=4)$. (d) Treatment of UB/OC-1 cells with L-NAME or SC-791, inhibitor of iNOS or COX-2, respectively, resulted in partial inhibition of cisplatin-induced apoptosis $(P<0.05, n=4)$. Data are presented as mean \pm S.E.M. The asterisks $\left(^{*}\right)$ and $\left({ }^{*}\right)$ indicate statistically significant difference from vehicle and cisplatin-treated cells, respectively

overall increase in immunolabeling could reflect labeling from resident and recruited immune cells, and resident cochlear non-immune cells. This conclusion is supported by the observation that UB/OC1 cells, a model of cochlear hair cells, could be induced to express CD14 and CD45 markers.

STAT1 is an important component of signal transduction pathways mediated through inflammatory cytokines. Maximal transcriptional activation of STAT1 involves $\mathrm{Tyr}^{701}$ and Ser ${ }^{727}$ phosphorylation, ${ }^{26}$ the latter involving mitogen-activated protein kinases (MAPKs). ${ }^{27}$ Our data indicate that ROS have a critical role in mediating the $\mathrm{Ser}^{727}$ phosphorylation of STAT1 in UB/OC-1 cultures and the cochlea. STAT1 Ser ${ }^{727}$ phosphorylation and activity were reduced by inhibition or knockdown of NADPH oxidase, implicating ROS in this process. ROS are generally linked to increased lipid peroxidation, providing the rationale for using antioxidants to treat cisplatin ototoxicity. ${ }^{28}$ We suggest dual roles of ROS in the cochlea, promoting both oxidative stress and inflammation. Cisplatin did not increase STAT1 $\mathrm{Tyr}^{701}$ phosphorylation in UB/OC-1 cells, even though both sites were phosphorylated in cells exposed to IFN- $\gamma$.

Several mechanisms are believed to mediate cisplatininduced apoptosis. The 'traditional' mechanism involves covalent binding of cisplatin to guanine bases on DNA; the formation of inter- and intra-strand chain cross-linking; and induction of p53, cell-cycle arrest and apoptosis. ${ }^{29}$ ROS generated by cisplatin could increase lipid peroxidation, which alters enzymes and structural proteins, and direct the cell to an apoptotic pathway. As indicated in this study, cisplatininduced apoptosis could involve the inflammatory pathway. This latter pathway likely contributes significantly to cisplatin ototoxicity, based on the in vivo effectiveness of etanercept, an antagonist of TNF- $\alpha$. It is still unclear whether DNA damage contributes to the cisplatin-mediated activation of STAT1 in UB/OC-1 cells and the cochlea. Interestingly, knockdown of STAT1 by siRNA attenuated cisplatin-mediated p53 activation, suggesting that STAT1 is an essential regulator of p53 activity. The rapid activation of STAT1 by cisplatin contrasts with the slower pace of induction of DNA-repair enzymes, such as xeroderma pigmentosium A (XPA), by this drug. ${ }^{30}$ Activation of STAT1 was abolished following knockdown of NOX3 by siRNA, suggesting that ROS generation is the primary mediator of STAT1 activation ${ }^{4}$ in UB/OC-1 cells and the cochlea. Activation of STAT1 was observed following activation of TRPV1 in the cochlea. This mode of STAT1 activation was dependent on ROS but was independent of p53 activation. ${ }^{4}$

We showed that cisplatin increases the expression of COX-2, iNOS and TNF- $\alpha$, downstream targets of STAT1, which likely contributed to inflammation and apoptosis in the cochlea. Inhibition of COX-2, iNOS or TNF- $\alpha$ led to reduced cisplatin-mediated apoptosis of UB/OC-1 cells, whereas 

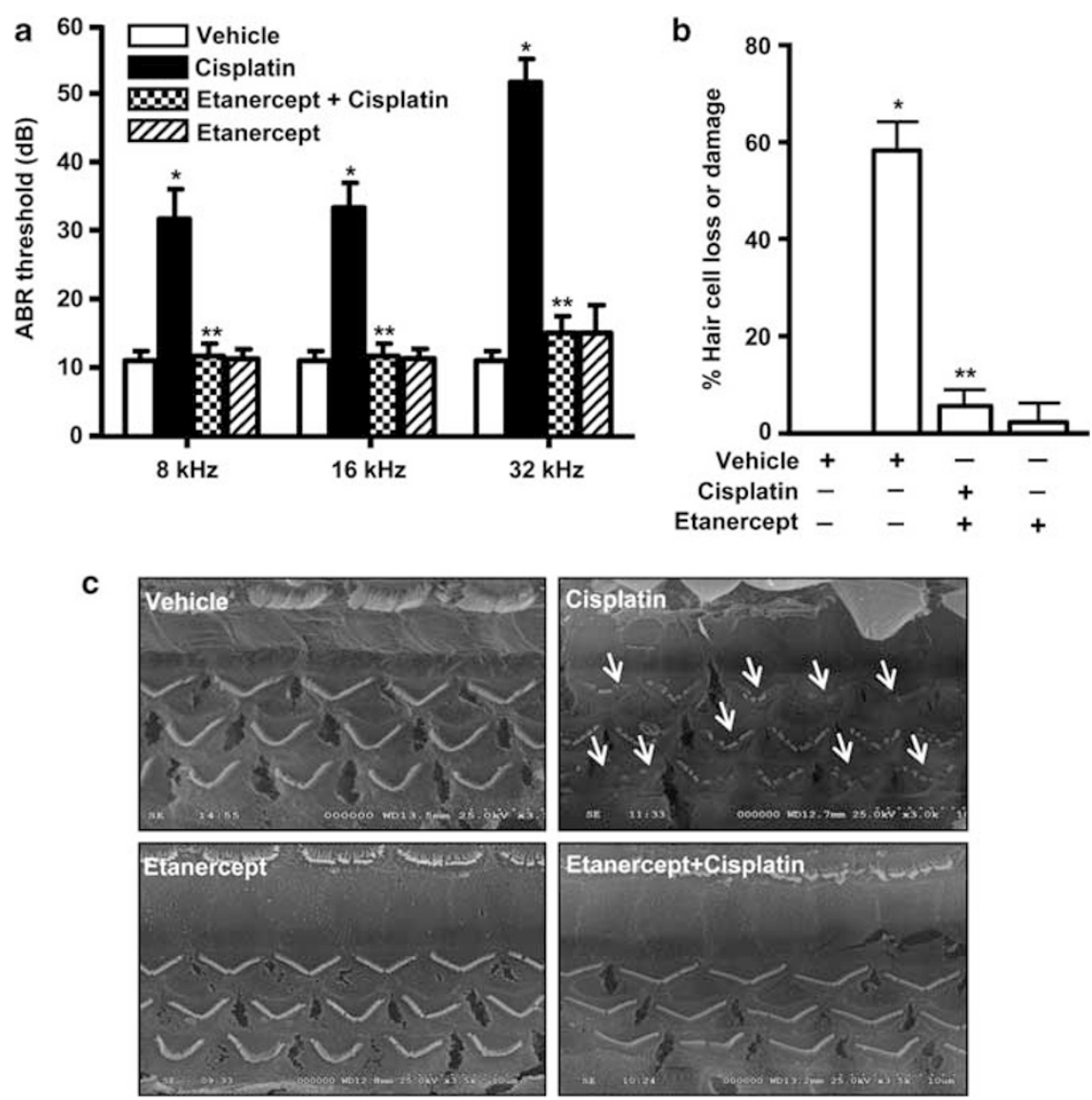

Figure 8 Inhibition of TNF- $\alpha$ by etanercept suppresses cisplatin-induced hearing loss. (a) Rats were administered vehicle or etanercept by trans-tympanic injections, followed by vehicle or cisplatin $30 \mathrm{~min}$ later. $A B R$ thresholds were recorded in these groups of rats before and after $72 \mathrm{~h}$ of cisplatin administration (11 mg/kg, i.p.). Etanercept significantly reduced cisplatin-induced increase in $\mathrm{ABR}$ thresholds $(P<0.05, n=5)$. (b) Scanning electron microscopic studies were performed in cochleae isolated from rats treated as above. The representative image shows damage to OHCs (white arrows) by cisplatin, which is prevented by etanercept. (c) Quantitative analysis of the scanning electron micrographs images. Data are presented as mean \pm S.E.M. The asterisks $\left(^{*}\right)$ and $\left(^{* *}\right)$ indicate statistically significant difference from the vehicle or the cisplatin treatment group, respectively $(P<0.05, n=5)$

inhibition of TNF- $\alpha$ (by etanercept) reduced cisplatin-induced hearing loss. These data suggest that targeting STAT1dependent inflammation is a useful approach for treating cisplatin ototoxicity. The effectiveness of etanercept against cisplatin ototoxicity would suggest that TNF- $\alpha$ is a key inflammatory mediator of $\mathrm{OHC}$ damage/death and ototoxicity. TNF- $\alpha$ also has a significant role in cisplatin-induced nephrotoxicity. Inhibition of TNF- $\alpha$-converting enzyme (TACE), the enzyme, which cleaves and releases TNF- $\alpha$ into the circulation, reduced cisplatin-mediated kidney injury, thereby implicating TNF- $\alpha$ in this process. ${ }^{31}$

In previous studies, we have successfully used round window or trans-tympanic delivery of siRNAs to the cochlea to effect otoprotection. ${ }^{3,4,32}$ While these siRNAs produced efficient knockdown of their target proteins, it is yet unclear how they enter the cells of the cochlea. Administration of siRNAs through the intravenous route produced a significant accumulation of the intact siRNA in the proximal tubules of the kidneys. $^{33}$ This selective accumulation of siRNAs was presumably due to their uptake through the oligonucleotide transporter localized specifically to the proximal tubules. As the kidneys and cochlea share a number of similarities, ${ }^{28}$ the cochlea could also express these oligonucleotide transporters to effect efficient knockdown of different genes linked to ototoxicity.

Targeting inflammation by using corticosteroids or etanercept has been an effective strategy in treating immunemediated inner ear disease (IMIED). Etanercept reduces hearing loss associated with experimentally induced labyrinthitis in guinea pigs sensitized to keyhole limpet hemocyanin $^{34}$ and inflammation in the endolymphatic sac, ${ }^{7}$ two animal models of IMIED. The benefits of etanercept were comparable to corticosteroids against experimentally induced labyrinthitis. ${ }^{35}$ Patients with autoimmune-induced hearing loss respond positively to anti-inflammatory agents such as glucocorticoids. ${ }^{36}$ In addition, patients with immune-mediated cochleovestibular disorders showed significant improvement when administered etanercept. ${ }^{37}$

In summary, our data demonstrate the utility of targeting cochlear STAT1 or STAT1-regulated genes by the transtympanic route for treating cisplatin ototoxicity. Localized delivery of drugs to the cochlea could be performed on an outpatient basis and would limit the widespread immune suppression and potential drug-drug interactions characterized by systemic administration of these agents. The ease of trans-tympanic drug delivery suggests that this could 
represent a useful route of administration of anti-inflammatory agents to treat hearing loss.

\begin{abstract}
Materials and Methods
Drugs and reagents. Cisplatin, EGCG, L-NAME, DPI and TRI reagent were purchased from Sigma-Aldrich (St. Louis, MO, USA), whereas the $2^{\prime}, 7^{\prime}$ dichlorodihydrofluorescein diacetate $\left(\mathrm{H}_{2} \mathrm{DCFDA}\right)$ dye was from EMD Biosciences (Gibbstown, NJ, USA). SC-791 (COX-2 inhibitor) was purchased from Calbiochem (La Jolla, CA, USA). Etanercept (Enbrel) was purchased from Amgen Wyeth (Thousand Oaks, CA, USA). The various antibodies used and their dilutions were as follows: STAT1 (1:5000), iNOS (1:1000), COX-2 (1:1000), TNF- $\alpha$ (1:500), CD45 (1:100; from Abcam, Cambridge, MA, USA), CD14 (1:100; from Santa Cruz Biotechnology, Santa Cruz, CA, USA), p-STAT1 (1: 1000) (both Ser ${ }^{727}$ and Tyr ${ }^{701}$ ), caspase-3 (1:1000), caspase-9 $(1: 1000)$ and Bax $(1: 1000)$ (Cell Signaling Technology Inc., Danvers, MA, USA); goat anti-rabbit, donkey anti-goat and goat anti-mouse secondary antibodies (Santa Cruz Biotechnology); and fluorescent tagged (Dylight-488 and TRITC) secondary antibodies (Jackson Immuno Laboratories, West Grove, PA, USA).
\end{abstract}

Animal procedures and sample collection. Male Wistar rats (200$250 \mathrm{~g}$ ) were used for this study. Pretreatment ABRs were performed immediately before trans-tympanic application of either siRNA against STAT1 or a scramble sequence, which served as a control for $48 \mathrm{~h}$. Cisplatin $(11 \mathrm{mg} / \mathrm{kg}$ ) was administered intraperitoneally $48 \mathrm{~h}$ after siRNA administration. Another group of animals were treated with etanercept or vehicle trans-tympanically $30 \mathrm{~min}$ prior to the cisplatin administration. There was no evidence of middle ear effusion or infection in these animals. Post-treatment ABRs were then performed $72 \mathrm{~h}$ following cisplatin administration. Cochleae were dissected and used for total RNA, perfused with $2.5 \%$ glutaraldehyde for S.E.M. or with $4 \%$ paraformaldehyde for immunohistochemistry. All animal procedures used were approved by the SIU Laboratory Animal Care and Use Committee.

Trans-tympanic administration of siRNA. The procedure performed is similar to that used previously in our laboratory in rats. ${ }^{4} \mathrm{~A} 50-\mu \mathrm{l}$ volume of solution was injected into the middle ear (siRNA was re-suspended in $50 \mu \mathrm{l}$ of sterile water for the desired concentration). The rat was then left undisturbed for $15 \mathrm{~min}$ with the treated ear facing up. This procedure was then repeated for the other ear.

Evoked potentials. ABRs were determined as described previously. ${ }^{3}$ Animals were tested with a stimulus intensity series that was initiated at $10 \mathrm{~dB}$ SPL and reached a maximum at $90 \mathrm{~dB} \mathrm{SPL}$, with $10-\mathrm{dB}$ increments. The auditory stimuli included tone bursts at 8,16 and $32 \mathrm{kHz}$, with a 5 -ms plateau and a 1 -ms rise/fall time presented at a rate of $5 / \mathrm{s}$. Threshold was defined as the lowest intensity capable of evoking a reproducible, visually detectable response, with two distinct waveforms and minimum amplitude of $0.5 \mu \mathrm{V}$.

Morphological studies by scanning electron microscopy. Immediately after completion of post-treatment ABRs, deeply sedated rats were euthanized, their cochleae were harvested and were processed as described previously. ${ }^{3}$ Sputter-coated cochleae were then viewed and photographed with a Hitachi S-500 scanning electron microscope (Hitachi Ltd, Tokyo, Japan).

Hair cell count. Hair cell counts were performed as described previously. ${ }^{3}$ Two representative areas of the basal turn, middle turn, and apex and hook portion were photographed. In each area, $\mathrm{OHCs}$ were counted in an area that was 10 pillar cell heads in length. The results are presented as the percent hair cell damage per cochlear turn. At least three cochleae from different animals per treatment group were used.

Processing of cochleae for immunohistochemistry. Cochleae were perfused with $4 \%$ paraformaldehyde, decalcified for $4-6 \mathrm{~h}$ by rapid decalcification (RapidCal Immuno, BBC Biochemical, Detroit, MI, USA), paraffin-embedded and sectioned. Immunolabeling studies were performed as described previously. ${ }^{3,4}$ Slides were then imaged using a Leica confocal microscope (Buffalo Grove, IL, USA).

Immunocytochemistry. To detect nuclear translocation of p-STAT1 after cisplatin treatment by immunofluorescence staining, UB/OC-1 cells were first plated in a 12-well plate. After the cells adhered to the plate surface, they were transfected with either scramble siRNA ( $5 \mathrm{nM}$ ) or STAT1 siRNA ( $10 \mathrm{nM})$ by using the RNAfectin transfection reagent for $48 \mathrm{~h}$. At the end of $48 \mathrm{~h}$ the cells were treated with cisplatin $(2.5 \mu \mathrm{M})$ for another $45 \mathrm{~min}$. After the treatment, the cells were fixed with $4 \%$ paraformaldehyde (Sigma), followed by washing with $1 \times$ PBS (phosphate-buffered saline). Coverslips were then incubated with solution-A-5\% donkey serum (Jackson Immuno Laboratories) and $0.5 \%$ Triton-X (Sigma) in PBS for $30 \mathrm{~min}$ at room temperature. Primary antibody against p-STAT1 (1:300 dilution) in solution-A was then added and incubated for $2 \mathrm{~h}$ at $37^{\circ} \mathrm{C}$. After three washes with $1 \times \mathrm{PBS}$, the cells were incubated with a Dylight-488-labeled anti-rabbit secondary antibody (1:600 dilution) in the dark for $1 \mathrm{~h}$. After three washes with $1 \times$ PBS and two washes with fresh distilled water the coverslips were mounted on glass slides by using the Vectashield mounting medium containing DAPI (Vector Laboratories Inc., Burlingame, CA, USA) for nuclear staining, before examination under an Olympus fluorescence microscope.

siRNA sequences. The rodent set of siRNAs was designed based on the homologous sequences in the rat and mouse cDNA sequences. A custom siRNA was purchased from Qiagen (Valencia, CA, USA). Scramble siRNA was also procured from the Human/Mouse starter kit (Qiagen). Rodent NOX3 siRNA: Target sequence: $5^{\prime}$-AAGGTGGTGAGTCACCCATCT- $3^{\prime} .{ }^{3}$ Rodent STAT1 siRNA: Target sequence: $5^{\prime}$-AAGGAAAAGCAAGCGTAATCT-3' ${ }^{32}$

siRNA transfection. DNAfectin and RNAfectin (Applied Biological Materials Inc., Richmond, BC, Canada) were used for transfections of plasmids and siRNAs, respectively, according to the manufacturer's instructions. Briefly, UB/OC-1 cells were transfected with $10 \mathrm{nM}$ STAT1 and $5 \mathrm{nM}$ NOX3 siRNA or scramble siRNA in serum-free medium for $5-8 \mathrm{~h}$. The culture medium was then replaced with fresh medium for $48 \mathrm{~h}$. Cells were then treated accordingly.

RNA isolation and real-time RT-PCR. RNA was isolated from UB/OC-1 cell cultures as well as the rat cochleae by adding $1 \mathrm{ml}$ of TRI reagent to $100 \mathrm{mg}$ of each cochlea or $0.5 \mathrm{ml}$ of TRI reagent per well of each six-well plate, and real-time RT-PCR studies were also performed as described previously. ${ }^{3,4}$ The cycle number at which the sample reached the threshold fluorescent intensity was termed the cycle threshold $\left(C_{t}\right)$. The relative change in mRNA levels between untreated and the treated sample was measured using the following formula, $2^{\Delta \Delta C t} \cdot{ }^{38}$ Negative controls for both target gene and glyceraldehyde-3 phosphate dehydrogenase (GAPDH) were used for all reaction groups. Gene-specific primer pairs were used for the various reactions and mRNA expression levels were normalized to the levels of GAPDH. The primer sets were purchased from Sigma Genosys (St. Louis, MO, USA) and were as follows:

Rodent-Bax (sense): 5'-ATGGCTGGGGAGACACCTGA-3'; (antisense): 5'-GC AAAGTAGAAGAGGGCAACC-3';

Rodent-Bcl2 (sense): 5'-CCTTCTTTGAGTTCGGTG-3'; (antisense): 5'-GAGAC AGCCAGGAGAAAT-3'

Rodent-iNOS (sense): $5^{\prime}$-CATTCTACTACTACCAGATC-3'; (antisense): $5^{\prime}$-ATG TGCTTGTCACCACCAG-3'

Rodent-COX2 (sense): 5'-TGATCGAAGACTACGTGCAAC-3'; (antisense): 5'-GT ACTCCTGGTCTTCAATGTT-3'

Rodent-GAPDH (sense): 5'-ATGGTGAAGGTCGGTGTGAAC-3'; (antisense): 5'-TGTAGTTGAGGTCAATGAAGG-3'

Rodent-NOX3 (sense): 5'-GTGAACAAGGGAAGGCTCAT-3'; (antisense): 5'-GA CCCACAGAAGAACACGC- 3

Rodent-STAT1 (sense): 5'-CATGGAATCAGACAGTACCT-3'; (antisense): 5'-TC TGTACGGGATCTTCTTGGA-3'

Rodent-TNF- $\alpha$ (sense): $5^{\prime}$-CAGACCCTCACACTCAGATCA-3'; (antisense): $5^{\prime}$-TG AAGAGAACCTGGGAGTAGA-3'

Cell culture. Immortalized organ of Corti cells derived from the mouse, UB/OC-1 cells, were obtained from Dr. Matthew Holley (Institute of Molecular Physiology, Addison Building, Western Bank, Sheffield, UK) and cultured in RPMI-1640 supplemented with $10 \%$ Fetalclone-II serum (Hyclone laboratories, Inc., Logan, UT, USA), penicillin-streptomycin and normocin (Invitrogen, Carlsbad, CA, USA). The cultures were grown at $33^{\circ} \mathrm{C}$ in an incubator with $10 \% \mathrm{CO}_{2}$.

$\mathrm{H}_{2}$ DCFDA assay. ROS generation was measured with the green-fluorescent dye $\mathrm{H}_{2}$ DCFDA as described previously. ${ }^{3}$ Briefly, UB/OC- 1 cells were transfected with siRNAs (for $48 \mathrm{~h}$ ). The cells were then treated with cisplatin for $15 \mathrm{~min}$ followed 
by incubation with $5 \mu \mathrm{M} \mathrm{H}_{2}$ DCFDA dye for $15 \mathrm{~min}$. ROS generation was detected as green fluorescence by confocal microscopy.

Apoptosis detection by flow cytometry. Apoptotic cells were labeled and visualized by using the FITC-Annexin-V Apoptosis detection kit (BD Pharmingen, San Diego, CA, USA). Briefly, UB/OC-1 cells were transfected with either scramble or STAT1 siRNA for $48 \mathrm{~h}$ followed by treatment with cisplatin $(20 \mu \mathrm{M})$ for another $24 \mathrm{~h}$. At the end of the treatment, the cells were washed with PBS and harvested in a $0.5 \%$ trypsin/EDTA solution at $37^{\circ} \mathrm{C}$, centrifuged at $220 \times g$ for $5 \mathrm{~min}$ and then immediately re-suspended in the buffer provided in the kit. The cells $\left(1 \times 10^{5}\right.$ cells $\left./ 500 \mu l\right)$ were then maintained in the dark for $15 \mathrm{~min}$ at room temperature with $5 \mu \mathrm{l}$ of both FITC-conjugated Alexa-V and propidium iodide, and samples were analyzed immediately by flow cytometry (FACS Calibur; Becton Dickinson, San Jose, CA, USA). Results were analyzed by using the CellQuest software provided with the FACS machine. Early apoptotic cells are shown in the lower right-hand quadrant of each dot plot, whereas necrotic or late apoptotic cells are shown in the upper right-hand quadrant of the plot.

Flow cytometry for CD14 and CD45 expression. UB/OC-1 cell were treated with either vehicle, cisplatin $(2.5 \mu \mathrm{M} / \mathrm{ml})$ or IFN- $\gamma(250 \mathrm{U} / \mathrm{ml})$ for $24 \mathrm{~h}$. At the end of the 24-h incubation period, the cells were resuspended in a $1 \times \mathrm{PBS}+10 \%$ fetal calf serum $+1 \%$ sodium azide solution followed by staining with the unconjugated primary antibody solution (CD45 and CD14 1:100 in 3\% BSA in $1 \times \mathrm{PBS}$ ) at $4{ }^{\circ} \mathrm{C}$ for $30 \mathrm{~min}$. After washing the pellet with $1 \times \mathrm{PBS}$, the cells were stained with the secondary antibody solution (Dylight-488 goat anti-rabbit; $1: 200$ in $3 \% \mathrm{BSA}$ in $1 \times \mathrm{PBS}$ ) for $30 \mathrm{~min}$ in the dark at $4{ }^{\circ} \mathrm{C}$. Finally the pellet was resuspended in a $1 \times \mathrm{PBA}+3 \% \mathrm{BSA}+1 \%$ sodium azide solution and labeled cells were analyzed by flow cytometry (FACS Calibur; Becton Dickinson). The results were analyzed by using the CellQuest software provided with the FACS machine.

Plasmid and siRNA co-transfection. UB/OC-1 cells were simultaneously transfected with plasmid DNA (STAT1 p84/91; purchased from Panomics Inc., Fremont, CA, USA) and pGL3 Renilla, a gift from Dr. YY Mo (SIU School of Medicine), by using DNAfectin and siRNA (STAT1 or scramble) by using RNAifectin. Briefly, for each well of a 24-well plate: (1) Plasmid DNA mix: In $32 \mu$ l of serum-free media, $0.8 \mu \mathrm{g}$ of STAT1 luciferase plasmid and $0.1 \mu \mathrm{g}$ of pGL3 Renilla luciferase plasmid were diluted. A $2-\mu$ l volume of DNAfectin was diluted in $32 \mu \mathrm{l}$ of serum-free media. The DNAfectin mix was then added to the plasmid mix and gently mixed and incubated for $20 \mathrm{~min}$ (about $60 \mu \mathrm{l}$ total for each well). (2) siRNA mix: In $32 \mu \mathrm{l}$ of serum-free media, either STAT1 siRNA $(10 \mathrm{nM})$ or scramble siRNA $(5 \mathrm{nM})$ was mixed. A $2-\mu$ l volume of RNAfectin was diluted in $32 \mu \mathrm{l}$ of serum-free media. RNAfectin mix was added to the siRNA tube and gently mixed. This mixture was then incubated for $20 \mathrm{~min}$ (about $60 \mu \mathrm{l}$ total for each well). At the end of $20 \mathrm{~min}, 60 \mu \mathrm{l}$ of the plasmid mix and $60 \mu \mathrm{l}$ of siRNA mix were added to each well containing $130 \mu \mathrm{l}$ of serum-free media. The plate was then incubated at $33^{\circ} \mathrm{C}$ for $8 \mathrm{~h}$, after which serum-free media was replaced with whole media for another $36 \mathrm{~h}$.

Luciferase assay. UB/OC-1 cells transfected with plasmid and siRNA were used for this experiment. Pre-treatment with EGCG was performed for half an hour followed by treatment with cisplatin $(2.5 \mu \mathrm{M})$ for another $8 \mathrm{~h}$. Luciferase activity was assessed by using the Dual-Luciferase Reporter Assay kit (Promega, Madison, WI, USA) according to the manufacturer's protocol. Briefly, the cells were harvested by using the lysis buffer provided in the kit. A 25- $\mu$ l volume of the lysate was mixed with $25 \mu$ lof luciferase assay substrate and luciferase activity was measured by using a Berthold Detection Systems luminometer (Huntsville, AL, USA). To measure the activity of the control Renilla luciferase, $25 \mu \mathrm{l}$ of stop and glo substrate was then added to the lysate mix and luminescence was measured again. Renilla luciferase was used for normalization.

Western blot analysis. UB/OC-1 cells were homogenized in ice-cold $50 \mathrm{mM}$ Tris $\mathrm{HCl}, 10 \mathrm{mM} \mathrm{MgCl}$ and $1 \mathrm{mM}$ EDTA in the presence of a protease inhibitor mixture (Sigma) and phosphatase inhibitor-1 (Sigma). The whole-cell lysates were then used for western blotting as described previously. ${ }^{39}$ After transferring to nitrocellulose membranes, the blots were probed with different primary antibodies, followed by a horseradish peroxidase-tagged secondary antibody, and visualized by chemiluminescence detection (Pierce Biotechnology, Rockford, IL, USA) using charged-coupled device LAS 4000 (Fujifilm North America Corporation, Valhalla,
NY, USA). Densitometric analysis of blots was performed by using the MultiGauge version 2.0 software.

Statistical analysis. Data are presented as mean \pm S.E.M. Statistical significance of differences among groups were performed by either Student's $t$-test or analysis of variance followed by Tukey's post hoc test wherever appropriate.

\section{Conflict of Interest}

The authors declare no conflict of interest.

Acknowledgements. This research was supported by National Institutes of Health Grants R01 DC02396 (LPR), R15 CA135494 (VR) and F32 DC009950 (DM), and funds from SIU School of Medicine.

1. Rybak LP, Mukherjea D, Jajoo S, Ramkumar V. Cisplatin ototoxicity and protection: clinical and experimental studies. Tohoku J Exp Med 2009; 219: 177-186.

2. Bánfi B, Malgrange B, Knisz J, Steger K, Dubois-Dauphin M, Krause KH. NOX3, a superoxide-generating NADPH oxidase of the inner ear. J Biol Chem 2004; 279: 46065-46072.

3. Mukherjea D, Jajoo S, Whitworth C, Bunch JR, Turner JG, Rybak LP et al. Short interfering RNA against transient receptor potential vanilloid 1 attenuates cisplatin-induced hearing loss in the rat. J Neurosci 2008; 28: 13056-13065.

4. Mukherjea D, Jajoo S, Kaur T, Sheehan KE, Ramkumar V, Rybak LP. Transtympanic administration of short interfering (si)RNA for the NOX3 isoform of NADPH oxidase protects against cisplatin-induced hearing loss in the rat. Antioxid Redox Signal 2010; 13: 589-598.

5. Kanzaki J, Ouchi T. Steroid-responsive bilateral sensorineural hearing loss and immune complexes. Arch Otorhinolaryngol 1981; 230: 5-9.

6. Yoshida K, Ichimiya I, Suzuki M, Mogi G. Effect of proinflammatory cytokines on cultured spiral ligament fibrocytes. Hear Res 1999; 137: 155-159.

7. Satoh H, Firestein GS, Billings PB, Harris JP, Keithley EM. Proinflammatory cytokine expression in the endolymphatic sac during inner ear inflammation. $J$ Assoc Res Otolaryngol 2003; 4: 139-147.

8. Kim HJ, So HS, Lee JH, Park C, Lee JB, Youn MJ et al. Role of proinflammatory cytokines in cisplatin-induced vestibular hair cell damage. Head Neck 2008; 30: 1445-1156.

9. So H, Kim H, Kim Y, Kim E, Pae HO, Chung HT et al. Evidence that cisplatin-induced auditory damage is attenuated by downregulation of pro-inflammatory cytokines via Nrf2/ HO-1. J Assoc Res Otolaryngol 2008; 9: 290-306.

10. Watanabe K, Inai S, Jinnouchi K, Bada S, Hess A, Michel $O$ et al. Nuclear-factor kappa B (NF- $\kappa$ B)-inducible nitric oxide synthase (iNOS/NOS II) pathway damages the stria vascularis in cisplatin-treated mice. Anticancer Res 2002; 22: 4081-4085.

11. So H, Kim H, Lee JH, Park C, Kim Y, Kim E et al. Cisplatin cytotoxicity of auditory cells requires secretions of proinflammatory cytokines via activation of ERK and NF- $\kappa \mathrm{B}$. J Assoc Res Otolaryngol 2007; 8: 338-355.

12. Schmitt NC, Rubel EW, Nathanson NM. Cisplatin-induced hair cell death requires STAT1 and is attenuated by epigallocatechin gallate. J Neurosci 2009; 29: 3843-3851.

13. Ohmori $Y$, Hamilton TA. Requirement for STAT1 in LPS-induced gene expression in macrophages. J Leukoc Biol 2001; 69: 598-604.

14. Xuan YT, Guo $Y$, Zhu $Y$, Han H, Langenbach R, Dawn B et al. Mechanism of cyclooxygenase-2 upregulation in late preconditioning. J Mol Cell Cardiol 2003; 35 : 525-537.

15. Sugawara I, Yamada H, Mizuno S. STAT1 knockout mice are highly susceptible to pulmonary mycobacterial infection. Tohoku J Exp Med 2004; 202: 41-50.

16. Yoshimura A. Signal transduction of inflammatory cytokines and tumor development. Cancer Sci 2006; 97: 439-447.

17. Porta C, Hadj-Slimane R, Nejmeddine M, Pampin M, Tovey MG, Espert L et al. Interferons alpha and gamma induce p53-dependent and p53-independent apoptosis, respectively. Oncogene 2005; 24: 605-615.

18. Townsend PA, Scarabelli TM, Davidson SM, Knight RA, Latchman DS, Stephanou A. STAT-1 interacts with p53 to enhance DNA damage-induced apoptosis. J Biol Chem 2004; 279: $5811-5820$

19. Goodisman J, Souid AK. Constancy in integrated cisplatin plasma concentrations among pedriatic patients. J Clin Pharmacol 2006; 46: 443-448.

20. Menegazzi M, Tedeschi E, Dussin D, Carcereri De Prati A, Cavalieri E, Mariotto $S$ et al. Anti-interferon gamma action of epigallocatechin-3-gallate mediated by specific inhibition of STAT1 activation. FASEB J 2001; 15: 1309-1311.

21. Simon AR, Rai U, Fanburg BL, Cochran BH. Activation of the JAK-STAT pathway by reactive oxygen species. Am J Physiol 1998; 275: C1640-C1652.

22. Watanabe $K$, Hess A, Bloch W, Michel $O$. Nitric oxide synthase inhibitor suppresses the ototoxic side effects of cisplatin in guinea pigs. Anticancer Drugs 2000; 11: 401-406. 
23. Hoshino T, Tabuchi K, Hirose $Y$, Uemaetomari I, Murashita H, Tobita T et al. The nonsteroidal anti-inflammatory drugs protect mouse cochlea against acoustic injury. Tohoku $\mathrm{J}$ Exp Med 2008; 216: 53-59.

24. Van Wijk F, Staecker H, Keithley E, Lefebvre PP. Local perfusion of the tumor necrosis factor alpha blocker infliximab to the inner ear improves autoimmune neurosensory hearing loss. Audiol Neurootol 2006; 11: 357-365.

25. Ulevitch RJ, Tobias PS. Receptor-dependent mechanism of cell stimulation by bacterial endotoxin. Annu Rev Immunol 1995; 13: 437-457.

26. Wen Z, Zhong Z, Darnell Jr JE. Maximal activation of transcription by Stat1 and Stat3 requires both tyrosine and serine phosphorylation. Cell 1995; 82: 241-250.

27. Xuan YT, Guo Y, Zhu Y, Wang OL, Rokosh G, Messing RO et al. Role of the protein kinase C-epsilon-Raf-1-MEK-1/2-p44/42 MAPK signaling cascade in the activation of signal transducers and activators of transcription 1 and 3 and induction of cyclooxygenase-2 after ischemic preconditioning. Circulation 2005; 112 : 1971-1978.

28. Rybak LP, Ramkumar V. Ototoxicity. Kidney Int 2007; 72: 931-935.

29. Jung Y, Lippard SJ. Direct cellular responses to platinum-induced DNA damage. Chem Rev 2007; 107: 1387-1407.

30. Kang TH, Lindsey-Boltz LA, Reardon JT, Sancar A. Circadian control of XPA and excision repair of cisplatin-DNA damage by cryptochrome and HERC2 ubiquitin ligase. Proc Natl Acad Sci USA 2010; 107: 4890-4895.

31. Ramesh G, Reeves WB. TNF- $\alpha$ mediates chemokine and cytokine expression and renal injury in cisplatin nephrotoxicity. J Clin Invest 2002; 110: 835-842.

32. Mukherjea D, Jajoo S, Sheehan KE, Kaur T, Sheth S, Bunch J et al. NOX3 NADPH oxidase couples transient receptor potential vanilloid 1 to STAT1-mediated inflammation and hearing loss. Antioxid Redox Signal 2011; 14: 999-1010.
33. Molitoris BA, Dagher PC, Sandoval RM, Campos SB, Ashush H, Fridman E et al. siRNA targeted to p53 attenuates ischemic and cisplatin-induced acute kidney injury. J Am Soc Nephrol 2009; 20: 1754-1764.

34. Wang X, Truong T, Billings PB, Harris JP, Keithley EM. Blockage of immune-mediated inner ear damage by etanercept. Oto Neurotol 2003; 24: 52-57.

35. Lobo D, Trinidad A, García-Berrocal JR, Verdaguer JM, Ramírez-Camacho R. TNF blockers do not improve the hearing recovery obtained with glucocorticoid therapy in an autoimmune experimental labyrinthitis. Eur Arch Otorhinolaryngol 2006; 263: 622-626.

36. Garcya-Berrocal JR, Ramỳrez-Camacho R, Trinidad A, Lobo D. Glucocorticoids: the best therapy for immune-mediated inner ear disease. Curr Top Steroid Res 2004; 4: 99-104.

37. Rahman MU, Poe DS, Choi HK. Etanercept therapy for immune-mediated cochleovestibular disorders: preliminary results in a pilot study. Otol Neurotol 2001; 22: 619-624.

38. Soong R, Beyser K, Basten O, Kalbe A, Rueschoff J, Tabiti K. Quantitative reverse transcription-polymerase chain reaction detection of cytokeratin 20 in non-colorectal lymph nodes. Clin Cancer Res 2001; 7: 3423-3429.

39. Jajoo S, Mukherjea D, Watabe K, Ramkumar V. Adenosine A(3) receptor suppresses prostate cancer metastasis by inhibiting NADPH oxidase activity. Neoplasia 2009; 11: $1132-1145$.

Cell Death and Disease is an open-access journal published by Nature Publishing Group. This work is licensed under the Creative Commons Attribution-Noncommercial-No Derivative Works 3.0 Unported License. To view a copy of this license, visit http://creativecommons.org/licenses/by-nc-nd/3.0/

Supplementary Information accompanies the paper on Cell Death and Disease website (http://www.nature.com/cddis) 